\title{
Study of correlation of microalbuminuria with glycemic status in diabetic nephropathy at a tertiary care center
}

\author{
Mohammed Siyadat Ali ${ }^{1}$, Mohammad Rafi ${ }^{*}$
}

${ }^{1}$ Professor and HOD, Shri Shankaracharya Institute of Medical Sciences, Junwani, Bhilai, District. Durg, Chattisgarh, INDIA. Email: warangalmetro@gmail.com

\begin{abstract}
Background: Diabetic nephropathy (DN) develops in patients with several years' medical history of diabetes and renal failure. $\mathrm{HbAlc}$ is currently accepted as the most informative biomarker of glycemic control in subjects with diabetes and is highly prognostic for long-term diabetes-related complications such as microalbuminuria. In present study we aimed to correlate microalbuminuria with glycemic status in patients with diabetic nephropathy. Material and Methods: Present study was prospective, cross sectional type conducted in patients with Type 2 diabetis melitus with diabetic nephropathy , with $\mathrm{HbAlc}$ value $>6.3 \%$. Results: The study is conducted in 120 diagnosed cases of Type II Diabetes Mellitus with diabetic nephropathy. Mean age of patients was $53.25 \pm 6.11$ years. Male to female ratio was $1.26: 1$. Out of total 120 patients, $64(53 \%)$ had Normo-albuminuria while $56(47 \%)$ had micro-albuminuria. With increasing duration of disease, increase in patients with Micro-albuminuria was noted. In patients with less than 5 years duration $79 \%$ patients had Normo-albuminuria while $68 \%$ had micro-albuminuria when duration of disease was more than 15 years. In patients with glycated hemoglobin less than $8,92 \%$ patients had normo-albuminuria while $92 \%$ had micro-albuminuria when glycated hemoglobin was more than 12 . Duration of disease was positively corelated with micro-albuminuria. Similarly urinary albumin excretion was positively correlated with $\mathrm{HbAlc}$ and was statistically significant. Conclusion: Microalbuminuria in diabetes, which represents an earlier phase in the development of clinical nephropathy, increases with increased duration of diabetes mellitus as well as increased levels of glycated hemoglobin.

Key Words: microalbuminuria.
\end{abstract}

Address for Correspondence:

Dr. Mohammed Rafi, Professor and HOD, Mahaveer Institute of Medical Sciences, Shivareddypet, Vikarabad, Rangareddy district,

Telangana.

Email: warangalmetro@gmail.com

Received Date: 12/09/2019 Revised Date: 02/10/2019 Accepted Date: 20/11/2019

DOI: https://doi.org/10.26611/10021231

\begin{tabular}{|l|l|}
\hline \multicolumn{2}{|c|}{ Access this article online } \\
\hline Quick Response Code: & Website: \\
\hline & www.medpulse.in \\
& \\
\hline
\end{tabular}

\section{INTRODUCTION}

Diabetes Mellitus (DM) is a chronic, widely prevalent endocrine disease, which is characterized by hyperglycemia due to defects in insulin secretion, insulin action or both1. It is also estimated that there were 415 million people with DM worldwide in the year 2015 and this number is expected to increase to 640 million people by 20402 . It is also expected that much of this increase in prevalence rate will occur in developing countries. As the number of persons with diabetes increases, the development of microvascular complications like retinopathy, nephropathy and neuropathy also rises. According to a report by the World Health Organization (WHO), the prevalence rates of nephropathy after 15 years of diabetes ranged between 17.7 and $56.6 \%$ in men and between 11.9 and $71 \%$ in women3. Diabetic nephropathy (DN) develops in patients with several years' medical history of diabetes and renal failure. However, research shows that patients with type 1 diabetes progress early to ESRD as compared to those with type $2 \mathrm{DM}$. HbAlc is currently accepted as the most informative biomarker of glycemic control in subjects

\footnotetext{
How to cite this article: Mohammed Siyadat Ali, Mohammad Rafi. Study of correlation of microalbuminuria with glycemic status in diabetic nephropathy at a tertiary care center. MedPulse International Journal of Biochemistry. December 2019; 12(3): 76-79. https://www.medpulse.in/Biochemistry/
} 
with diabetes and is highly prognostic for long-term diabetes-related complications such as microalbuminuria ${ }^{4}$. Microalbuminuria has also emerged as an important risk factor for left ventricular hypertrophy, myocardial infarction, stroke, peripheral vascular diseases and retinopathy, independent of blood pressure. In present study we aimed to correlate microalbuminuria with glycemic status in patients with diabetic nephropathy.

\section{MATERIAL AND METHODS}

Present study was prospective, cross sectional type conducted in out-patient department of Medicine, XXX medical college, XXXX. Study duration was 6 months (April 2019 to September 2019). Institutional ethical committee permission taken for present study.

Inclusion criteria - Patients with Type 2 diabetis melitus, with $\mathrm{HbAlc}$ value $>6.3 \%$, with diabetic nephropathy willing to participate in present study.

Diabetic nephropathy is defined by increased urinary albumin excretion (UAE) in the absence of other renal diseases. It is categorized into two stages: microalbuminuria $(\mathrm{UAE} \geq 20 \mathrm{microg} / \mathrm{min}$ and $\leq$ $199 \mathrm{microg} / \mathrm{min}$ ) and macroalbuminuria (UAE $\geq 200$ $\operatorname{microg} / \mathrm{min}) 5$.

\section{RESULTS}

The study is conducted in 120 diagnosed cases of Type II Diabetes Mellitus with diabetic nephropathy, irrespective of duration of Diabetes and sex taken randomly from the Outpatient and admitted patients under department of Medicine. Microalbuminuria includes a range of urinary excretion of albumin of 20 to $200 \mathrm{mg} / \mathrm{L}$ or 20 to $200 \mu \mathrm{g} / \mathrm{min}$. While normo-albuminuria considered as urinary excretion of albumin less than $20 \mathrm{mg} / \mathrm{L}$ or less than $20 \mu \mathrm{g} / \mathrm{min}$. patients with macroalbuminuria were already excluded. Patients were from age group of 40-60 years, mean age of patients was 53.25 \pm 6.11 years. Male to female ratio was $1.26: 1$. Out of total 120 patients, 64 (53\%) had Normo-albuminuria while 56 (47 \%) had micro-albuminuria (Table 1).

\begin{tabular}{cccc}
\multicolumn{5}{c}{ Table 1: Gender wise distribution of proteinuria } \\
\hline & Normo-albuminuria & Micro-albuminuria & Total \\
\hline Male & $36(54 \%)$ & $31(46 \%)$ & 67 \\
Female & $28(53 \%)$ & $25(47 \%)$ & 53 \\
\hline Total & $64(53 \%)$ & $56(47 \%)$ & 120 \\
\hline
\end{tabular}

Urinary albumin excretion was compared with duration of diabetes. With increasing duration of disease, increase in patients with Micro-albuminuria was noted. In patients with less than 5 years duration $79 \%$ patients had Normoalbuminuria while $68 \%$ had micro-albuminuria when duration of disease was more than 15 years. (Table 2).

\begin{tabular}{|c|c|c|c|}
\hline Duration (years) & Normo-albuminuria & Micro-albuminuria & Total \\
\hline$<5$ years & 22 (79 \%) & $6(21 \%)$ & 28 \\
\hline$\geq 5$ - 10 years & $16(64 \%)$ & $9(36 \%)$ & 25 \\
\hline$\geq 10-15$ years & 15 (45 \%) & $18(55 \%)$ & 33 \\
\hline$\geq 15$ years & $11(32 \%)$ & $23(68 \%)$ & 34 \\
\hline Total & $64(53 \%)$ & $56(47 \%)$ & 120 \\
\hline
\end{tabular}

We compared urinary albumin excretion with glycemic status of patients (HbAlc - glycated hemoglobin). With increasing values of glycated hemoglobin, increase in patients with micro-albuminuria was noted. In patients with glycated hemoglobin less than $8,92 \%$ patients had normo-albuminuria while $92 \%$ had micro-albuminuria when glycated hemoglobin was more than 12 (Table 3 ). 
Table 3: Prevalence of microalbminuria in relation to HbA1c level in T2DM

\begin{tabular}{cccc}
\hline HbA1c level (\%) & Normoalbuminuria & microalbuminuria & Total \\
\hline$<8$ & $45(92 \%)$ & $4(8 \%)$ & 49 \\
$8.1-10$ & $13(54 \%)$ & $11(46 \%)$ & 24 \\
$10.1-12$ & $4(18 \%)$ & $18(82 \%)$ & 22 \\
$\geq 12$ & $2(8 \%)$ & $23(92 \%)$ & 25 \\
\hline Total & $64(53 \%)$ & $56(47 \%)$ & 49 \\
\hline
\end{tabular}

We statistically compared urinary albumin excretion with duration of disease and HbAlc levels. Mean duration (years) of disease was $7.32 \pm 3.19$ in Normo-albuminuria patients while it was $9.27 \pm 4.98$ years in patients with microalbuminuria. Duration of disease was positively corelated with micro-albuminuria. Similarly urinary albumin excretion was positively correlated with $\mathrm{HbAlc}$ and was statistically significant.

Table 4: Correlation microalbuminuria with duration of disease and HbA1c levels

\begin{tabular}{cccc}
\hline Variable & Normo-albuminuria & Micro-albuminuria & P value \\
\hline Mean duration (years) & $7.32 \pm 3.19$ & $9.27 \pm 4.98$ & Statistically significant \\
Mean HbA1c level (\%) & $7.35 \pm 1.98$ & $8.45 \pm 2.09$ & Statistically significant \\
\hline
\end{tabular}

\section{DISCUSSION}

End-organ damage seen in dibetes melitus is maily due to microvascular changes. The magnitude of damage caused by these microvascular complications of diabetes stresses the need for sensitive markers of screening for retinopathy and nephropathy ${ }^{6}$. These microvascular complications are linked to the duration of diabetes mellitus, poor glycemic control and systolic hypertension ${ }^{7}$. Diabetic nephropathy also called as Kimmelsteil Wilson syndrome is characterized by a progressive increase in the excretion of protein particularly albumin, an early and continuing rise in blood pressure and a late decline in glomerular filtration rate (GFR) resulting in end stage renal disease. Staging of diabetic nephropathy is given in table-5.

Table 5: Staging of diabetic nephropathy

\begin{tabular}{|c|c|c|}
\hline Stage & staging by Tervaert et al. & staging by Gheith et al. \\
\hline 1 & $\begin{array}{l}\text { Glomerular basement membrane } \\
\text { thickening }\end{array}$ & $\begin{array}{c}\text { From onset to } 5 \text { years. Borderline GFR, no albuminuria, hypertension. But kidney } \\
\text { size increased by } 20 \% \text { along with an increase in renal plasma fow }\end{array}$ \\
\hline 2 & Mild or severe mesangial expansion & $\begin{array}{c}\text { From } 2 \text { years after onset with basement membrane thickening and mesangial } \\
\text { prolieration, normal GFR and no clinical symptoms }\end{array}$ \\
\hline 3 & Nodular sclerosis & $\begin{array}{l}\text { 5-10 years after onset with or without hypertension, with glomerular damage and } \\
\text { microalbuminuria }(30-300 \mathrm{mg} / \text { day })\end{array}$ \\
\hline 4 & $\begin{array}{c}\text { Advanced diabetic glomerulosclerosis that } \\
\text { includes tubulointerstitial lesions and } \\
\text { vascular lesions }\end{array}$ & Irreversible proteinuria, sustained hypertension and GFR below $60 \mathrm{ml} / \mathrm{min} / 1.73 \mathrm{~m} 2$ \\
\hline 5 & & End-stage kidney disease with GFR $<15 \mathrm{ml} / \mathrm{min} / 1.73 \mathrm{~m}$ \\
\hline
\end{tabular}

Multiple studies shown that, the sensitive marker for the detection of diabetic nephropathy is to estimate excretion of microalbumin in urine10. Microalbuminuria has also emerged as an important risk factor for left ventricular hypertrophy, myocardial infarction, stroke, peripheral vascular diseases and retinopathy, independent of blood pressure. Strong evidence exists that improved glycemic control is effective at lessening the risks of nephropathy, retinopathy and neuropathy in diabetes. Although microalbuminuria is a confirmatory test for diagnosis of diabetic nephropathy, not all patients progress to macroalbuminuria. In fact, some patients may regress to normoalbuminuria ${ }^{11}$. Progression and regression of kidney disease in type $2 \mathrm{DM}$ is highly variable as it is usually diagnosed with a secondary disorder, the onset of which is unrecorded. The UKPDS study reported microalbuminuria and reduced GFR in $38 \%$ and $29 \%$ patients respectively after a median follow-up of 15 years. In terms of progression, the same study reported a change from microalbuminurea-macroalbuminuria-ESKD at $2.8 \%$ and $2.3 \%$ per year respectively ${ }^{12}$. Microalbuminuria represents the simplest and most sensitive prognostic factor to evaluate the risk of overt nephropathy in diabetes, representing the first stage of progressive diabetic renal disease. However, it is not clear whether microalbuminuria represents an independent predictor or rather a marker of organ damage, since mechanisms linking microalbuminuria with end organ damage have not been fully explained ${ }^{13}$. Higher levels of $\mathrm{HbA1C}$ are associated with increased risk for development of microangiopathy in diabetic. This may be due to the fact that HbAlc has special affinity for oxygen thereby 
causing tissue anoxia and plays a role in causation of micro and macroangiopathy. Shonima Venugopal and Uma $M$ lyer showed statistically significant correlation of microalbuminuria and HbA1c level $(\mathrm{p}<0.05) 14$. Manjrekar et al has reported gradual increase in prevalence of microalbuminuria with similar increase in HbAlc level. ${ }^{15}$ Our results are similar with above studies. Meta-analysis for HbA1C Variability and the Risk of Renal Status Progression in Diabetes Mellitus16 indicated that $\mathrm{HbA1C}$ variability was independently associated with the development of microalbuminuria and the progression of renal status in both type 1 and 2 diabetes patients. Another analysis performed by Sugawara $e t a l^{17}$ also demonstrated that the intra-person standard deviation in A1C (A1C-SD) was an independent risk factor for the development of microalbuminuria in T2DM.

\section{CONCLUSION}

Microalbuminuria in diabetes, which represents an earlier phase in the development of clinical nephropathy, increases with increased duration of diabetes mellitus as well as increased levels of glycated hemoglobin. Regular screening for urinary microalbumin as well as $\mathrm{HbAlc}$ and good glycemic control is recommended to prevent diabetic nephropathy.

\section{REFERENCES}

1. American Diabetes Association Diagnosis and classification of diabetes mellitus. Diabetes care. 2008;31(Supplement 1):S55-S60.

2. IDF Diabetes Atlas. 7th ed. Brussels, Belgium: International Diabetes Federation; 2015. Available from: https://www.idf.org/e library/epidemiology research/diabetes atlas/13 diabetes atlas seventh edition.html.

3. Wirta O, Pasternack A, Mustonen J, Laippala P, Lähde Y: Retinopathy is independently related to microalbuminuria in type 2 diabetes mellitus. Clin Nephrol 1999, 51:329334

4. Borg R, Kuenen JC, Carstensen B, Zheng H, Nathan DM, et al. (2011) HbAlc and mean blood glucose show stronger associations with car $\neg$ diovascular disease risk factors than do postprandial glycaemia or glucose variability in persons with diabetes: the A1C-Derived Average Glucose (ADAG) study. Diabetologia 54(1): 69 72.

5. Sheuly F, Tania N, Saiful I, Quddusur R, Shahjada S. Microalbuminuria in Type 2 Diabetes and its Relationship with Glycosylated Hemoglobin. Curre Res Diabetes and Obes J. 2019; 10(4): 555795

6. Prevalence of small vessel and large vessel disease in diabetic patients from 14 centers. The World Health Organization Multinational Study of Vascular Disease in Diabetics. Diabetes Drafting Group. Diabetologia 1985, 28(Suppl):615-640.

7. Unnikrishnan RI, Rema M, Pradeepa R, Deepa M, Shanthirani CS, Deepa R, Mohan V: Prevalence and risk factors of diabetic nephropathy in an urban South Indian population: the Chennai Urban Rural Epidemiology Study (CURES 45). Diabetes Care 2007, 30:2019-2024.

8. Tervaert TW, Mooyaart AL, Amann K, Cohen AH, Cook HT, Drachenberg CB, et al. Pathologic classifcation of diabetic nephropathy. J Am Soc Nephrol. 2014;21(4):556-63. https://doi.org/10.1681/ASN.2010010010.

9. Gheith O, Farouk N, Nampoory N, Halim MA, Al-Otaibi T. Diabetic kidney disease: world wide diference of prevalence and risk factors. J Nephropharmacol. 2016;5(1):49-56.

10. Sobngwi E, Mbanya JC, Moukouri EN, Ngu KB: Microalbuminuria and retinopathy in a diabetic population of Cameroon. Diabetes Res Clin Pract 1999, 44:191-196.

11. Caramori ML, Fioretto P, Microalbuminuria er M. The need for early predictors of diabetic nephropathy risk: is albumin excretion rate sufcient? Diabetes. 2000;49:1399408.

12. Retnakaran R, Cull CA, Thorne KI, Adler AI, Holman RR. Risk factors for renal dysfunction in type 2 diabetes: UK prospective diabetes study 74 . Diabetes. 2006;55:1832-9.

13. Ochodnicky P, Henning RH, Van Dohhum RP, de Zeeuw D. Microalbuminuria and endothelial dysfunction: Emerging targets for primary prevention of end organ damage. J Cardiovasc Pharmacol 2006;47:S151 62.

14. Venugopal S, Iyer UM. Risk Factor Analysis and Prevalence of Microalbuminuria among Type 2 Diabetes Mellitus Subjects: The Need for Screening and Monitoring Microalbumin. Hip (cm). 2010;95(7):105-11.

15. ManjrekarPoornima A, Shenoy R, Hegde A. Laboratory Assessment of the Diabetes Scenario with Respect to HbA1c and Microalbuminuria. Journal of Clinical and Diagnostic Research. 2010;4:2489-94.

16. Cheng D, Fei Y, Liu Y, Li J, Xue Q, et al. (2014) HbA1C Variability and the Risk of Renal Status Progression in Diabetes Mellitus: A Meta-Analysis. PLoS ONE 9(12): e115509. doi:10. 1371/journal.pone.0115509

17. 6. Sugawara A, Kawai K, Motohashi S, Saito K, Kodama $\mathrm{S}$, et al. (2012) $\mathrm{HbA}(1 \mathrm{c})$ variability and the development of microalbuminuria in type 2 diabetes: Tsukuba Kawai Diabetes Registry 2. Diabetologia 55:2128-2131.

Source of Support: None Declared Conflict of Interest: None Declared 